\title{
The Inhibitory Action of the Extracts of Adathoda vasica, Eclipta alba, and Centella asiatica on the Corrosion of Mild Steel in Hydrochloric Acid Medium: A Comparative Study
}

\author{
M. Shyamala ${ }^{1}$ and P. K. Kasthuri ${ }^{2}$ \\ ${ }^{1}$ Department of Chemistry, Government College of Technology, Tamil Nadu, Coimbatore 641013, India \\ ${ }^{2}$ Department of Chemistry, L.R.G. Government Arts College for Women, Tamil Nadu, Tirupur 638604, India \\ Correspondence should be addressed to M. Shyamala, shyam786.399@rediffmail.com
}

Received 28 March 2011; Accepted 10 June 2011

Academic Editor: Ali Y. El-Etre

Copyright (C) 2012 M. Shyamala and P. K. Kasthuri. This is an open access article distributed under the Creative Commons Attribution License, which permits unrestricted use, distribution, and reproduction in any medium, provided the original work is properly cited.

\begin{abstract}
The Inhibitive action of the extracts of Adathoda vasica, Eclipta alba, and Centella asiatica on the corrosion of mild steel in $1 \mathrm{~N} \mathrm{HCl}$ has been studied using weight loss method, electrochemical methods, and hydrogen permeation method. Polarization method indicates that the plant extracts are under mixed control, that is, promoting retardation of both anodic and cathodic reactions. The impedance method reveals that charge-transfer process controls the corrosion of mild steel. The plant extracts obey Langmuir adsorption isotherm. Theoretical fitting of the corrosion data to the kinetic-thermodynamic model was tested to show the nature of adsorption. Physisorption mechanism has been proposed for the inhibition action of these plant extracts. The protective film formed on the surface was confirmed by SEM. From hydrogen permeation method, all the plant extracts were able to reduce the permeation current. Results obtained in all three methods were very much in good agreement in the order Eclipta alba $>$ Adathoda vasica $>$ Centella asiatica, and, among the three plant extracts studied, the maximum inhibition efficiency was found in Eclipta alba which showed $99.6 \%$ inhibition efficiency at $8.0 \% \mathrm{v} / \mathrm{v}$ concentration of the extract.
\end{abstract}

\section{Introduction}

Mild steel was the material of choice due to its characteristics of wide application in motor car bodies, machines, gears, pipes, tanks, and so forth and in most of the chemical industries. Hydrochloric acid and sulphuric acids are the medium generally being used for pickling mild steel. About $90 \%$ of pickling problems can be solved by introducing appropriate pickling inhibitor to the medium. The recent and growing trend is using plant extracts as corrosion inhibitor. Owing to strict environmental legislation, emphasis is being focused on development of naturally occurring substances as corrosion inhibitors [1]. Recently, many plant extracts have been reported to be very effective corrosion inhibitors for the protection of mild steel in acidic media [2-19]. In this study, the inhibition effect of the leaf extracts of Adathoda vasica (Adathodai), Eclipta alba (Karisalankanni), and Centella asiatica (Vallarai) on the corrosion of mild steel in $1 \mathrm{~N}$ hydrochloric acid was investigated using weight loss method, electrochemical methods, and hydrogen permeation method. There was no literature report on the studies of corrosion inhibition effect of the above plant extracts on mild steel in hydrochloric acid medium previously. From literature survey, it were found that the six plants selected for investigation was found to contain some alkaloids or hydroxyl organic compounds like sterols, tannins, and so forth. The aqueous extracts of these plants were prepared because alkaloids or hydroxyl organic compounds are easily soluble in water, and moreover due to the biodegradability, ecofriendliness, less toxicity, cost-effectiveness, easy availability, environmentally safe, and highly stable nature in acidic solutions, it was used to study the corrosion inhibition effect on mild steel in acid medium.

\section{Experimental Procedure}

2.1. Preparation of Mild Steel Specimen. Mild steel strips were mechanically cut into strips of size $4.5 \mathrm{~cm} \times 2 \mathrm{~cm} \times 0.2 \mathrm{~cm}$ 
containing the composition of $0.14 \%$ C, $0.35 \% \mathrm{Mn}, 0.17 \%$ $\mathrm{Si}, 0.025 \% \mathrm{~S}, 0.03 \% \mathrm{P}$, and the remainder $\mathrm{Fe}$ and provided with a hole of uniform diameter to facilitate suspension of the strips in the test solution for weight loss method. For electrochemical studies, mild steel strips of the same composition but with an exposed area of $1 \mathrm{~cm}^{2}$ were used. Mild steel strips were polished mechanically with emery papers of $1 / 0$ to $4 / 0$ grades, subsequently degreased with trichloroethylene or acetone and finally with deionized water, and stored in the desiccator. Accurate weight of the samples was taken using electronic balance.

2.2. Preparation of the Plant Extract. The leaves of the Adathoda vasica, Eclipta alba, and Centella asiatica were taken and cut into small pieces, and they were dried in an air oven at $80^{\circ} \mathrm{C}$ for $2 \mathrm{~h}$ and ground well into powder. From this, $10 \mathrm{~g}$ of the sample was refluxed in $100 \mathrm{~mL}$ distilled water for $1 \mathrm{~h}$. The refluxed solution was then filtered carefully, the stock solution was prepared from the collected filtrate and prepared the desired concentrations by dilution with $1 \mathrm{~N} \mathrm{HCl}$ and the concentration of the stock solution is expressed in terms of $\%(\mathrm{v} / \mathrm{v})$. From the stock solution, 2\%$10 \%$ concentration of the extract was prepared using $1 \mathrm{~N}$ hydrochloric acid. The aqueous extracts of these plants were prepared because alkaloids/hydroxyl organic compounds present in the leaves of these plants are easily hydrolysable and moreover have highly stable nature in acidic solutions. Similar kind of preparation has been reported in studies using aqueous plant extracts in the recent years [20-28].

2.3. Weight Loss Method. The pretreated specimens' initial weights were noted and were immersed in the experimental solution (in triplicate) with the help of glass hooks at $30^{\circ} \mathrm{C}$ for a period of $3 \mathrm{~h}$. The experimental solution used was $1 \mathrm{~N} \mathrm{HCl}$ in the absence and presence of various concentrations of the plant extracts. After three hours, the specimens were taken out, washed thoroughly with distilled water, and dried completely, and their final weights were noted. From the initial and final weights of the specimen, the loss in weight was calculated and tabulated. From the weight loss, the corrosion rate (mmpy), inhibition efficiency (\%), and surface coverage $(\theta)$ of plant extracts was calculated using the formula

$$
\text { Corrosion rate }(\mathrm{mmpy})=\frac{K W}{A t D},
$$

where $K=8.76 \times 10^{4}$ (constant), $W$ is weight loss in $g, A$ is area in $\mathrm{cmm}^{2}, t$ is time in hours and $D$ is density in $\mathrm{gm} / \mathrm{cmm}^{3}$ (7.86),

$$
\begin{gathered}
\text { Inhibition efficiency }(\%)=\frac{\mathrm{CR}_{B}-\mathrm{CR}_{I}}{\mathrm{CR}_{B}} \times 100, \\
\text { Surface coverage }(\theta)=\frac{\mathrm{CR}_{B}-\mathrm{CR}_{I}}{\mathrm{CR}_{B}},
\end{gathered}
$$

where $\mathrm{CR}_{B}$ and $\mathrm{CR}_{I}$ are corrosion rates in the absence and presence of the inhibitors.
2.4. Potentiodynamic Polarization Method. Potentiodynamic polarization measurements were carried out using electrochemical analyzer. The polarization measurements were made to evaluate the corrosion current, corrosion potential, and Tafel slopes. Experiments were carried out in a conventional three-electrode cell assembly with working electrode as mild steel specimen of 1 sq.cm.area which was exposed and the rest being covered with red lacquer, a rectangular $\mathrm{Pt}$ foil as the counter electrode, and the reference electrode as SCE. Instead of salt, bridge a luggin capillary arrangement was used to keep SCE close to the working electrode to avoid the ohmic contribution. A time interval of 10-15 minutes was given for each experiment to attain the steadystate open-circuit potential. The polarization was carried from a cathodic potential of $-800 \mathrm{mV}$ (versus SCE) to an anodic potential of $-200 \mathrm{mV}$ (versus SCE) at a sweep rate of $1 \mathrm{mV}$ per second. From the polarization curves, Tafel slopes, corrosion potential, and corrosion current were calculated. The inhibitor efficiency was calculated using the formula,

$$
\mathrm{IE}(\%)=\frac{I_{\text {Corr }}-I_{\text {Corr }}^{*}}{I_{\text {Corr }}} \times 100,
$$

where $I_{\text {corr }}$ and $I_{\text {corr }}^{*}$ are corrosion current in the absence and presence of inhibitors.

2.5. Electrochemical Impedance Method. The electrochemical AC-impedance measurements were also performed using electrochemical analyzer. Experiments were carried out in a conventional three-electrode cell assembly as that used for potentiodynamic polarization studies. A sine wave with amplitude of $10 \mathrm{mV}$ was superimposed on the steady open circuit potential. The real part $\left(Z^{\prime}\right)$ and the imaginary part $\left(Z^{\prime \prime}\right)$ were measured at various frequencies in the range of $100 \mathrm{KHz}$ to $10 \mathrm{MHz}$. A plot of $Z^{\prime}$ versus $Z^{\prime \prime}$ was made. From the plot, the charge transfer resistance $\left(R_{t}\right)$ was calculated, and the double layer capacitance was then calculated using

$$
C_{\mathrm{dl}}=\frac{1}{2 \pi f_{\max } R_{t}},
$$

where $R_{t}$ is charge transfer resistance, and $C_{\mathrm{dl}}$ is double layer capacitance. The experiments were carried out in the absence and presence of different concentrations of inhibitors. The percentage of inhibition efficiency was calculated using

$$
\mathrm{IE}(\%)=\frac{R_{t}^{*}-R_{t}}{R_{t}^{*}} \times 100,
$$

where $R_{t}^{*}$ and $R_{t}$ are the charge transfer resistance in the presence and absence of inhibitors.

2.6. Hydrogen Permeation Method. The behaviour of the inhibitors with regard to hydrogen permeation can be understood by measuring the permeation current with and without inhibitors. An inhibitor can be considered as completely effective only if it simultaneously inhibits metal dissolution and hydrogen penetration into the metal [29]. Hydrogen permeation study has been taken up with an idea of screening the inhibitors with regard to their effectiveness 
on the reduction of hydrogen uptake. Hence, the hydrogen permeation study was carried out using an adaptation of the modified Devanathan-Stachurski two compartment cell assembly $[30,31]$ in $1 \mathrm{~N} \mathrm{HCl}$ medium in the absence and presence of optimum concentration of the extracts. Similar kind of study is reported in the works of Quraishi and Rawat [32].

2.7. Surface Examination Studies. Surface examination of mild steel specimens in the absence and presence of the optimum concentration of the extracts immersed for $3 \mathrm{~h}$ at $30^{\circ} \mathrm{C}$ was studied using JEOL-Scanning electron microscope (SEM) with the magnification of 1000x specimens.

\section{Results and Discussion}

3.1. Weight Loss Studies. The various corrosion parameters such as corrosion rate (CR), inhibition efficiency (IE), and surface coverage $(\theta)$ were obtained from weight loss method $1 \mathrm{~N}$ hydrochloric acid in the absence and presence of various concentrations of the plant extracts ranging from $2 \%$ to $10 \% \mathrm{v} / \mathrm{v}$ and listed in Table 1 .

It was found that the optimum concentration for Adathoda vasica was found to be $6 \% \mathrm{v} / \mathrm{v}$ with maximum inhibition efficiency of $99.0 \%$, Eclipta alba, at $8 \% \mathrm{v} / \mathrm{v}$ with maximum inhibition efficiency of $99.6 \%$ and Centella asiatica at $10 \% \mathrm{v} / \mathrm{v}$ with maximum inhibition efficiency of $85.3 \%$ for a period of 3 hours of immersion time. This result indicates that the plant extracts could act as good corrosion inhibitors.

3.1.1. Effect of Immersion Time at $30^{\circ} \mathrm{C}$. The effect of immersion time on corrosion rate and inhibition efficiency of the plant extracts with an optimum concentration at $30^{\circ} \mathrm{C}$ studied as given in Table 2 shows that the inhibition efficiency of the extract slightly decreased with the increase of immersion time from 3 to $24 \mathrm{~h}$ and reveals that the plant extracts showed maximum efficiency at $3 \mathrm{~h}$ of immersion time which is sufficient for the pickling process.

3.2. Potentiodynamic Polarization Studies. Electrochemical corrosion kinetic parameters such as corrosion potential $\left(E_{\text {corr }}\right)$, corrosion current $\left(I_{\text {corr }}\right)$, anodic and cathodic Tafel slopes $\left(b_{a}\right.$ and $\left.b_{c}\right)$, and percentage efficiency (IE) for the corrosion of mild steel in $1 \mathrm{~N} \mathrm{HCl}$ at $30^{\circ} \mathrm{C}$ in the absence and presence of different concentrations of the plant extract are given in Table 3, and its corresponding polarization curves are shown in Figure 1. Potentiodynamic polarization studies revealed that the corrosion current density $\left(I_{\text {corr }}\right)$ markedly decreased with the addition of the extract and the corrosion potential shifts to less negative values upon addition of the plant extract. Moreover, the values of anodic and cathodic Tafel slopes $\left(b_{a}\right.$ and $\left.b_{c}\right)$ are slightly changed indicating that this behavior reflects the plant extracts ability to inhibit the corrosion of mild steel in $1 \mathrm{~N} \mathrm{HCl}$ solution via the adsorption of its molecules on both anodic and cathodic sites, and, consequently, the extracts act through mixed mode of inhibition $[20,21]$. It was observed that with increase in concentration of the plant extract from $2 \%$ to $10 \%$, the maximum inhibition efficiency of $99.2 \%$ was observed for Adathoda vasica at an optimum concentration of $6 \%$ in v/v, for Eclipta alba extract with $99.7 \%$ at $8 \% \mathrm{v} / \mathrm{v}$, and Centella asiatica with $85.7 \%$ at $10 \% \mathrm{v} / \mathrm{v}$ of the extract.

3.3. Electrochemical Impedance Studies. impedance measurements were studied to evaluate the charge-transfer resistance $\left(R_{t}\right)$ and double-layer capacitance $\left(C_{\mathrm{dl}}\right)$, and through these parameters the inhibition efficiency was calculated. Figure 2 shows the Impedance diagrams for mild steel in $1 \mathrm{~N} \mathrm{HCl}$ with different concentrations of the plant extract, and the impedance parameters derived from these investigations are given in Table 4.

From Figure 2, the obtained impedance diagrams are almost in a semicircular appearance, indicating that the charge-transfer process mainly controls the corrosion of mild steel. Deviations of perfect circular shape are often referred to the frequency dispersion of interfacial impedance. This anomalous phenomenon may be attributed to the inhomogeneity of the electrode surface arising from surface roughness or interfacial phenomena. In fact, in the presence of the plant extracts, the values of $R_{t}$ have enhanced and the values of double-layer capacitance are also brought down to the maximum extent. The decrease in $C_{\mathrm{dl}}$ shows that the adsorption of the inhibitors takes place on the metal surface in acidic solution.

For Adathoda vasica extract, the maximum $R_{t}$ value of $285.23 \Omega \mathrm{cm}^{2}$ and minimum $C_{\mathrm{dl}}$ value of $7.65 \mu \mathrm{F} / \mathrm{cm}^{2}$ are obtained at an optimum concentration of $6 \%$ in $\mathrm{v} / \mathrm{v}$ with a maximum inhibition efficiency of $97.3 \%$. For Eclipta alba extract, the maximum $R_{t}$ value of $358.80 \Omega \mathrm{cm}^{2}$ and minimum $C_{\mathrm{dl}}$ value of $6.00 \mu \mathrm{F} / \mathrm{cm}^{2}$ are obtained at an optimum concentration of $8 \%$ in $\mathrm{v} / \mathrm{v}$ with a maximum inhibition efficiency of $97.9 \%$. For Centella asiatica extract, the maximum $R_{t}$ value of $54.32 \Omega \mathrm{cm}^{2}$ and minimum $C_{\mathrm{dl}}$ value of $39.88 \mu \mathrm{F} / \mathrm{cm}^{2}$ are obtained at an optimum concentration of $10 \%$ in $\mathrm{v} / \mathrm{v}$ with a maximum inhibition efficiency of $86.0 \%$. A good agreement is observed between the results of weight loss method and electrochemical methods (potentiodynamic polarization method and impedance method) in the order Eclipta alba $>$ Adathoda vasica $>$ Centella asiatica.

3.4. Effect of Temperature. The effect of temperature on the corrosion rate of mild steel in free acid and in the presence of the optimum concentration of the inhibitors (plant extracts) was studied in the temperature range of $30^{\circ} \mathrm{C}$ to $80^{\circ} \mathrm{C}$, using the weight loss measurements and given in Table 5. It was found that the rates of mild steel corrosion, in free and inhibited acid solutions, increase with increase in temperature, but the corrosion rate is much decreased for inhibited acid solution than the uninhibited acid solution. Consequently, the inhibition efficiency of the extract decreases with the increasing temperature. This result suggests a physical adsorption of the extract compounds on the mild steel surface. It also revealed that the extract was adsorbed on the mild steel surface at all temperatures 
TABLE 1: Corrosion parameters obtained from weight loss measurements for mild steel in $1 \mathrm{~N} \mathrm{HCl} \mathrm{containing} \mathrm{various} \mathrm{concentrations} \mathrm{of} \mathrm{the}$ plant extracts.

\begin{tabular}{|c|c|c|c|c|}
\hline Name of the plant extract & Conc. of the extract $(\%$ in $v / v)$ & Corrosion rate (mmpy) & Inhibition efficiency (\%) & Surface coverage $(\theta)$ \\
\hline \multirow{6}{*}{ Adathoda vasica } & Blank & 30.67 & - & - \\
\hline & 2.0 & 1.78 & 94.2 & 0.9419 \\
\hline & 4.0 & 1.17 & 96.2 & 0.9618 \\
\hline & 6.0 & 0.30 & 99.0 & 0.9902 \\
\hline & 8.0 & 0.35 & 98.8 & 0.9885 \\
\hline & 10.0 & 0.58 & 98.1 & 0.9811 \\
\hline \multirow{6}{*}{ Eclipta alba } & Blank & 30.67 & - & - \\
\hline & 2.0 & 2.90 & 90.5 & 0.9054 \\
\hline & 4.0 & 1.98 & 93.5 & 0.9354 \\
\hline & 6.0 & 0.98 & 96.8 & 0.9680 \\
\hline & 8.0 & 0.12 & 99.6 & 0.9960 \\
\hline & 10.0 & 0.12 & 99.6 & 0.9960 \\
\hline \multirow{6}{*}{ Centella asiatica } & Blank & 30.67 & - & - \\
\hline & 2.0 & 12.82 & 58.2 & 0.5820 \\
\hline & 4.0 & 10.79 & 64.8 & 0.6482 \\
\hline & 6.0 & 8.55 & 72.1 & 0.7212 \\
\hline & 8.0 & 6.56 & 78.6 & 0.7861 \\
\hline & 10.0 & 4.50 & 85.3 & 0.8532 \\
\hline
\end{tabular}

TABle 2: Effect of immersion time on percentage inhibition efficiency of mild steel in $1 \mathrm{~N} \mathrm{HCl}$ at $30^{\circ} \mathrm{C}$ in the presence of optimum concentration of the plant extracts.

Name of the plant extract with optimum conc.

Inhibition efficiency (\%)

Time (h)

\begin{tabular}{lcccccccc} 
& 3 & 6 & 9 & 12 & 15 & 18 & 21 & 24 \\
\hline $6 \%$ v/v of Adathoda vasica & 99.0 & 98.2 & 96.6 & 96.2 & 95.5 & 94.4 & 93.6 & 92.7 \\
$8 \%$ v/v of Eclipta alba & 99.6 & 98.5 & 98.0 & 97.3 & 96.5 & 96.0 & 95.3 & 94.8 \\
$10 \%$ v/v of Centella asiatica & 85.3 & 84.8 & 84.3 & 78.6 & 71.4 & 70.8 & 68.3 & 67.1 \\
\hline
\end{tabular}

TABLE 3: Potentiodynamic polarization parameters for mild steel in $1 \mathrm{~N} \mathrm{HCl}$ containing various concentrations of the plant extracts.

\begin{tabular}{|c|c|c|c|c|c|c|}
\hline \multirow{2}{*}{$\begin{array}{l}\text { Name of the } \\
\text { plant extract }\end{array}$} & \multirow{2}{*}{$\begin{array}{l}\text { Conc. of extract } \\
(\% \text { in } \mathrm{v} / \mathrm{v})\end{array}$} & \multirow{2}{*}{$E_{\text {corr }}(\mathrm{V})$} & \multirow{2}{*}{$I_{\text {corr }}\left(\mathrm{mA} / \mathrm{cm}^{2}\right)$} & \multicolumn{2}{|c|}{ Tafel slope mV/decade } & \multirow{2}{*}{$\begin{array}{l}\text { Inhibition } \\
\text { efficiency (\%) }\end{array}$} \\
\hline & & & & $b_{a}$ & $b_{c}$ & \\
\hline Blank & - & -0.510 & 3.57 & 78 & 122 & - \\
\hline \multirow{5}{*}{ Adathoda vasica } & 2.0 & -0.512 & 0.21 & 78 & 124 & 94.1 \\
\hline & 4.0 & -0.491 & 0.14 & 76 & 122 & 96.1 \\
\hline & 6.0 & -0.493 & 0.02 & 74 & 120 & 99.2 \\
\hline & 8.0 & -0.493 & 0.02 & 74 & 120 & 99.2 \\
\hline & 10.0 & -0.508 & 0.06 & 76 & 122 & 97.2 \\
\hline \multirow{5}{*}{ Eclipta alba } & 2.0 & -0.494 & 0.32 & 80 & 126 & 91.0 \\
\hline & 4.0 & -0.502 & 0.20 & 78 & 124 & 94.4 \\
\hline & 6.0 & -0.494 & 0.10 & 76 & 126 & 97.2 \\
\hline & 8.0 & -0.496 & 0.01 & 74 & 122 & 99.7 \\
\hline & 10.0 & -0.482 & 0.06 & 78 & 124 & 98.3 \\
\hline \multirow{5}{*}{ Centella asiatica } & 2.0 & -0.492 & 1.47 & 76 & 128 & 58.8 \\
\hline & 4.0 & -0.491 & 1.22 & 78 & 126 & 65.8 \\
\hline & 6.0 & -0.493 & 0.97 & 80 & 122 & 72.8 \\
\hline & 8.0 & -0.470 & 0.74 & 74 & 126 & 79.3 \\
\hline & 10.0 & -0.492 & 0.51 & 76 & 124 & 85.7 \\
\hline
\end{tabular}




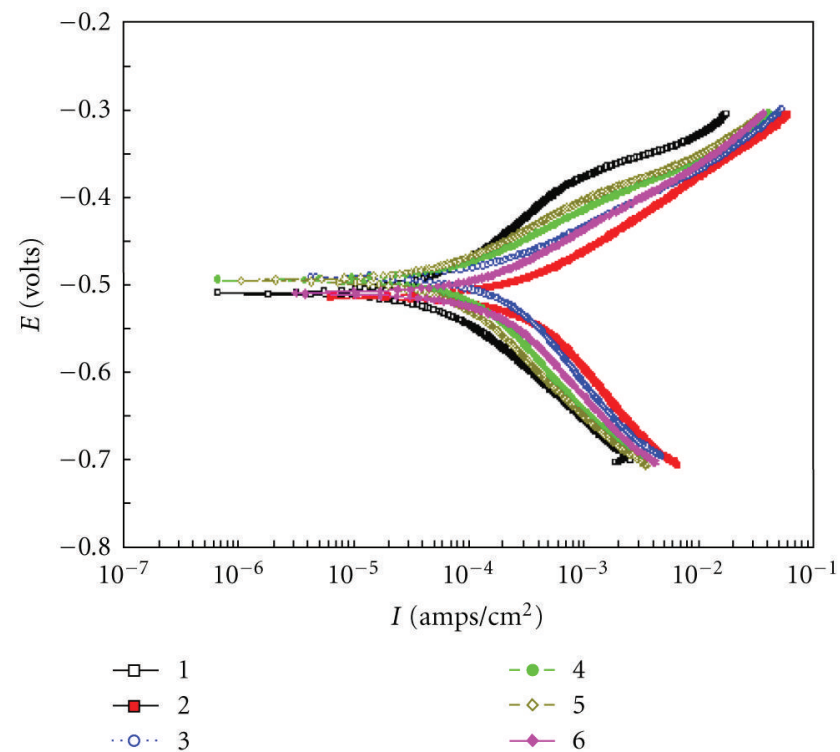

(a)

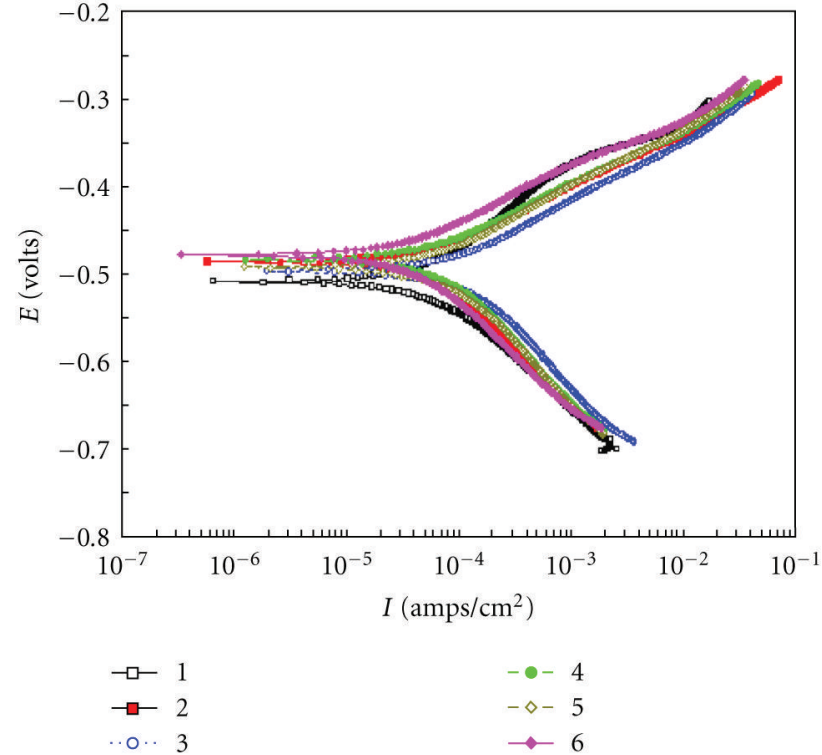

(b)

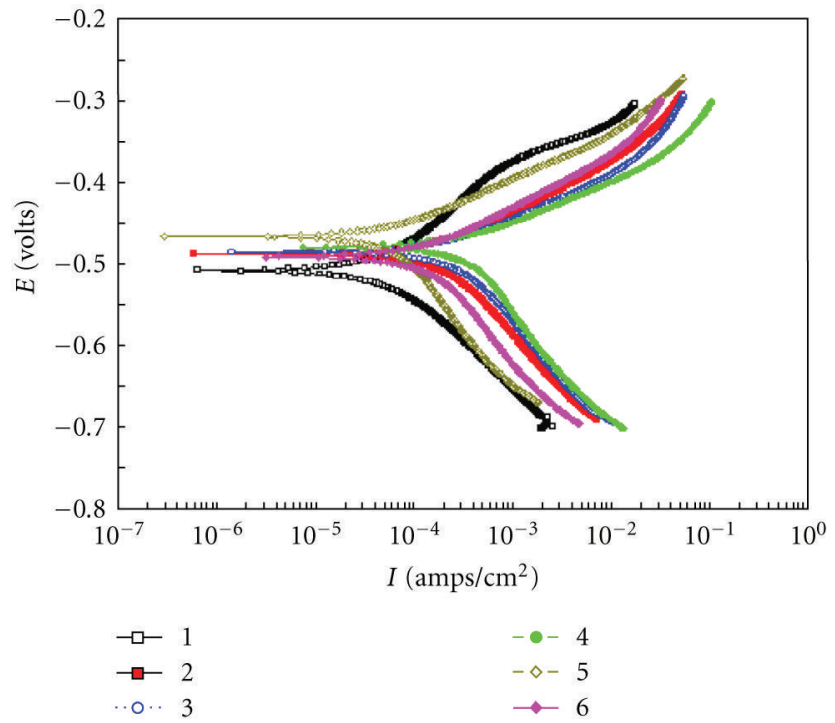

(c)

Figure 1: (1) Blank (2) $2.0(\% \mathrm{v} / \mathrm{v})(3) 4.0(\% \mathrm{v} / \mathrm{v})(4) 6.0(\% \mathrm{v} / \mathrm{v})(5) 8.0(\% \mathrm{v} / \mathrm{v})(6) 10.0(\% \mathrm{v} / \mathrm{v})$. Potentiodynamic polarization curves for mild steel in $1 \mathrm{~N} \mathrm{HCl}$ solution in the absence and presence of various concentrations of the plant extracts (a) Adathoda vasica (b) Eclipta alba and (c) Centella asiatica.

studied. A similar observation was seen in the studies of ElEtre [3].

3.5. Kinetics and Mechanism of Corrosion Inhibition. The major phytochemical constituents present in Adathoda vasica are the alkaloids Vasicine and Vasicinone (Figure 3), the major phytochemical constituent present in Centella asiatica is Asiaticoside, a triterpene glycoside (Figure 4), and the major phytochemical constituent present in Eclipta alba are Wedelolactone, $\beta$-sitosterol, Stigmasterol (Figures 5(a), 5(b), and 5(c)), and also an alkaloid Ecliptine [33-35]. Inspection of the chemical structures of the phytochemical constituents reveals that these compounds are easily hydrolysable and the compounds can adsorb on the metal surface via the lone pair of electrons present on their oxygen atoms and make a barrier for charge and mass transfer leading to decreasing the interaction of the metal with the corrosive environment. As a result, the corrosion rate of the metal was decreased. The formation of film layer essentially blocks discharge of $\mathrm{H}^{+}$and dissolution of metal ions. Due to electrostatic interaction, the protonated constituent's molecules are adsorbed (physisorption) and high inhibition is expected. Acid pickling inhibitors containing organic $\mathrm{N}, \mathrm{S}$, and $\mathrm{OH}$ groups behave similarly to inhibit corrosion $[36,37]$. 


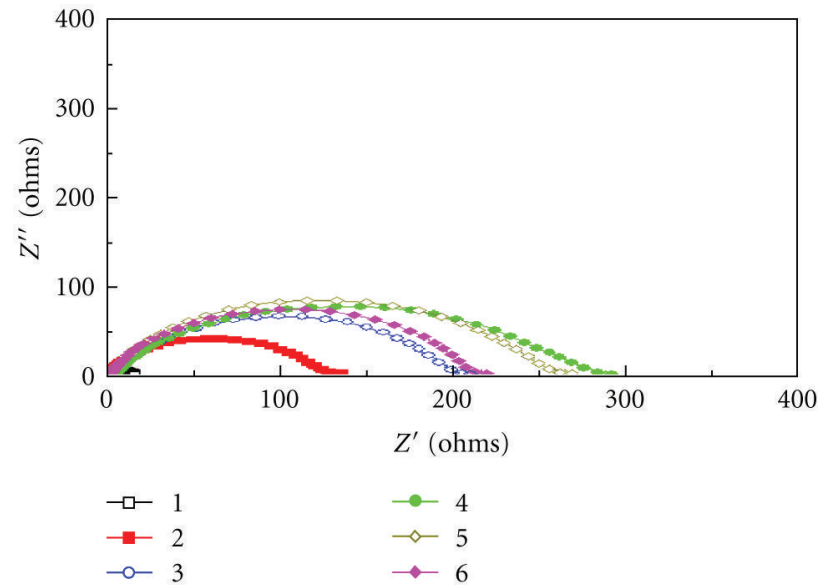

(a)

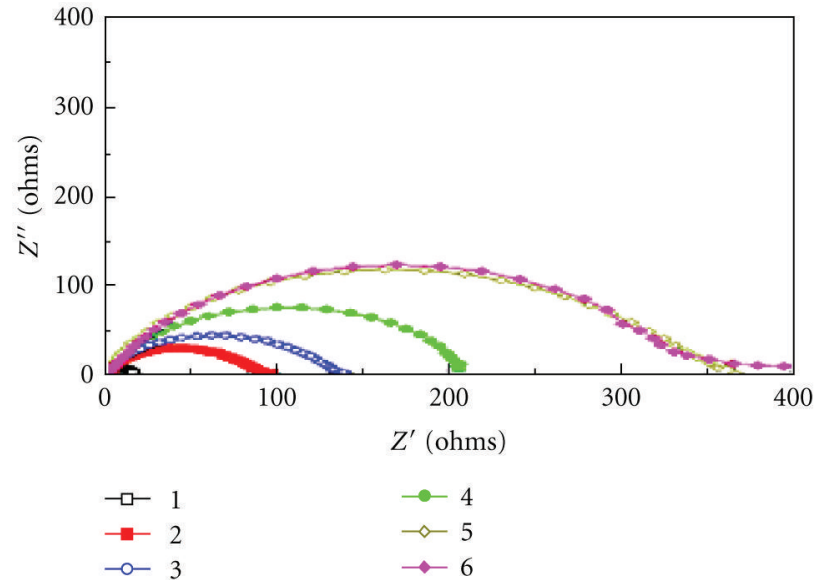

(b)

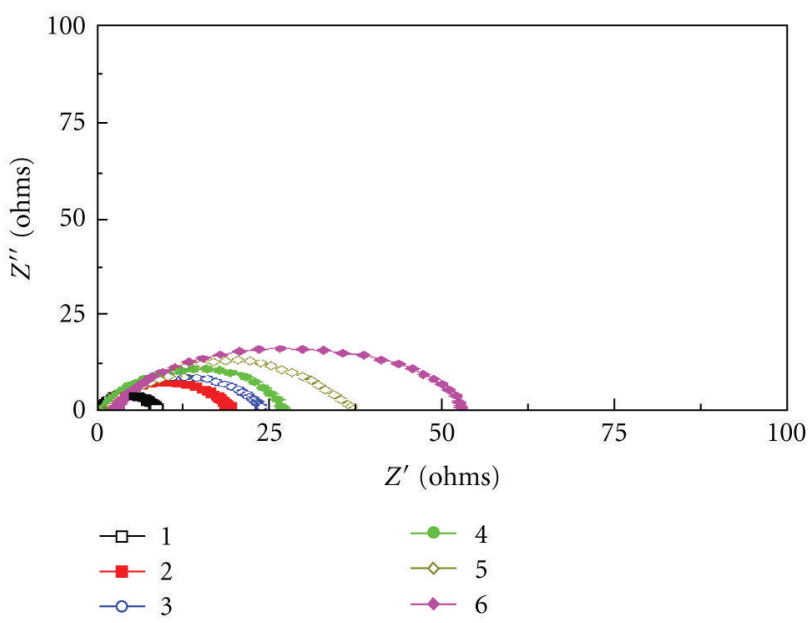

(c)

Figure 2: (1) Blank, (2) 2.0 (\% in v/v), (3) 4.0 (\% in v/v), (4) 6.0 (\% v/v), (5) 8.0 (\% in v/v), (6) 10.0 (\% in v/v). Impedance diagrams for mild steel in $1 \mathrm{~N} \mathrm{HCl}$ solution in the absence and presence of various concentrations of the plant extract (a) Adathoda vasica, (b) Eclipta alba, and (c) Centella asiatica.

TABLE 4: Impedance parameters for the corrosion of mild steel in $1 \mathrm{~N} \mathrm{HCl}$ in the absence and presence of various concentrations of the plant extracts at $30^{\circ} \mathrm{C}$.

\begin{tabular}{lcccc}
\hline Name of the plant extract & Conc. of extract $(\%$ in $\mathrm{v} / \mathrm{v})$ & $R_{t}\left(\Omega \mathrm{cm}^{2}\right)$ & $C_{\mathrm{dl}}\left(\mu \mathrm{F} / \mathrm{cm}^{2}\right)$ & Inhibition efficiency $(\%)$ \\
\hline Blank & - & 7.58 & 285.34 & $(\%)$ \\
\hline & 2.0 & 126.51 & 17.01 & 94.0 \\
Adathoda vasica & 4.0 & 200.34 & 10.72 & 96.2 \\
& 6.0 & 285.23 & 7.65 & 97.3 \\
& 8.0 & 255.35 & 8.44 & 97.0 \\
& 10.0 & 208.34 & 10.25 & 96.4 \\
Eclipta alba & 2.0 & 87.86 & 24.52 & 91.4 \\
& 4.0 & 136.49 & 15.86 & 94.4 \\
& 6.0 & 207.32 & 10.45 & 96.3 \\
& 8.0 & 358.80 & 6.00 & 97.9 \\
& 10.0 & 356.80 & 118.02 & 97.9 \\
& 2.0 & 18.32 & 96.61 & 78.6 \\
& 4.0 & 22.35 & 61.51 & 72.5 \\
& 6.0 & 27.54 & 39.88 & 78.4 \\
\end{tabular}


TABLE 5: Corrosion rate for the mild steel in $1 \mathrm{~N} \mathrm{HCl}$ at different temperatures obtained by weight loss method in the absence of the inhibitor and presence of the optimum concentration of the plant extracts.

\begin{tabular}{|c|c|c|c|}
\hline Name of the plant & Temperature $\left({ }^{\circ} \mathrm{C}\right)$ & Corrosion rate (mmpy) & Inhibition efficiency (\%) \\
\hline \multirow{6}{*}{ Blank } & 30 & 30.67 & \\
\hline & 40 & 50.12 & \\
\hline & 50 & 70.79 & \\
\hline & 60 & 108.43 & \\
\hline & 70 & 125.89 & \\
\hline & 80 & 177.82 & \\
\hline \multirow{6}{*}{$6 \%$ in v/v of Adathoda vasica } & 30 & 0.30 & 99.0 \\
\hline & 40 & 0.60 & 98.8 \\
\hline & 50 & 1.26 & 98.2 \\
\hline & 60 & 2.63 & 97.6 \\
\hline & 70 & 5.25 & 95.8 \\
\hline & 80 & 10.02 & 94.4 \\
\hline \multirow{6}{*}{$8 \%$ in v/v of Eclipta alba } & 30 & 0.12 & 99.6 \\
\hline & 40 & 0.62 & 98.7 \\
\hline & 50 & 1.78 & 97.5 \\
\hline & 60 & 4.47 & 95.8 \\
\hline & 70 & 11.22 & 93.7 \\
\hline & 80 & 23.00 & 87.1 \\
\hline \multirow{6}{*}{$10 \%$ in v/v of Centella asiatica } & 30 & 4.50 & 85.32 \\
\hline & 40 & 7.32 & 85.39 \\
\hline & 50 & 10.40 & 85.30 \\
\hline & 60 & 15.91 & 85.32 \\
\hline & 70 & 18.52 & 85.28 \\
\hline & 80 & 28.21 & 84.14 \\
\hline
\end{tabular}<smiles>[CH][C@@H]1[CH]N2Cc3ccccc3N=C2C1O</smiles>

1<smiles>O=c1c2ccccc2nc2n1CCC2O</smiles>

2
FIgURE 3: (1) Vasicine (2) Vasicinone.

The inhibition of the corrosion of mild steel in $1 \mathrm{~N} \mathrm{HCl}$ medium with addition of different concentrations of the extract can be explained by the adsorption of the components of the plant extracts on the metal surface. Inhibition efficiency (IE) is directly proportional to the fraction of the surface covered by the adsorbed molecules $(\theta)$. Therefore, $(\theta)$ with the extract concentration specifies the adsorption isotherm that describes the system and gives the relationship between the coverage of an interface with the adsorbed species and the concentration of species in solution. The values of the degree of surface coverage $(\theta)$ were evaluated at different concentrations of the inhibitors in $1 \mathrm{~N} \mathrm{HCl}$ solution. Attempts were made to fit $\theta$ values to various adsorption isotherm. An inhibitor is found to obey Langmuir, if a plot of $\log \theta / 1-\theta$ versus $\log C$ is linear. Similarly, for Temkin plot $\theta$ versus $\log C$, for BDM plot $(\log C-\log \theta / 1-\theta)$ versus $\theta^{3 / 2}$ and for Frumkin plot $\log \theta /(1-\theta) C$ versus $\theta$ will be linear. On examining, the adsorption of different concentrations of Adathoda vasica, Eclipta alba, and Centella asiatica extracts on the surface of mild steel in $1 \mathrm{~N}$ hydrochloric acid was found to obey Langmuir adsorption isotherm. The Langmuir adsorption isotherm plot for the adsorption of various concentrations of the plant extracts is shown in Figure 6.

Theoretical fitting of the corrosion data to the kineticthermodynamic model was tested to show the nature of adsorption. The standard free energy of adsorption $\Delta G_{\text {ads }}^{o}$ which can characterize the interaction of adsorption molecules and metal surface was calculated

$$
\ln K=\ln \frac{1}{55.5}-\frac{\Delta G_{\mathrm{ads}}^{o}}{R T}
$$

where one molecule of water is replaced by one molecule of inhibitor and the numerical value $(1 / 55.5)$ in the equation stands for the molarity of water.

The value of $K$ can be calculated using

$$
K=\frac{\theta}{(1-\theta) C} .
$$




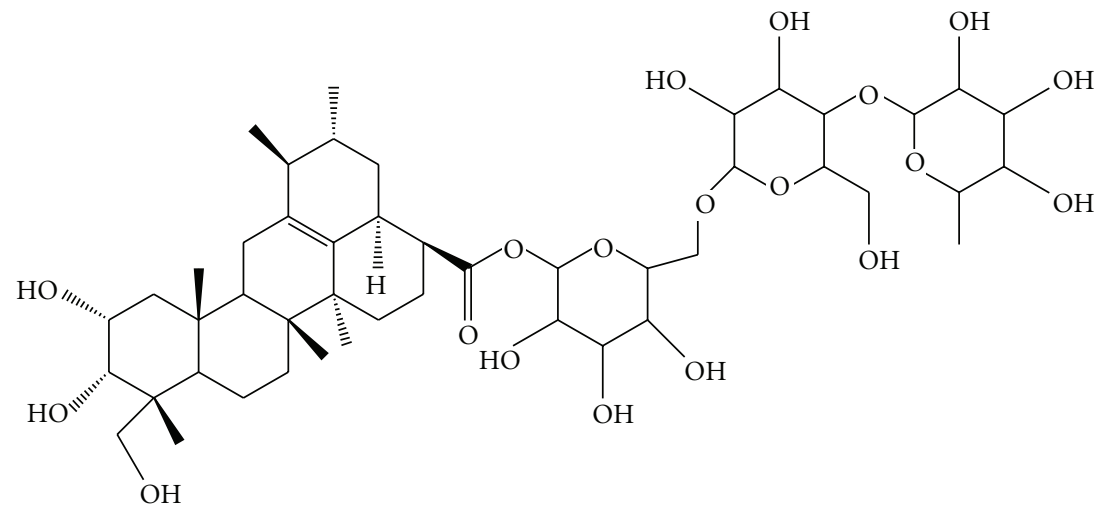

Figure 4: Asiaticoside.<smiles>COc1cc(O)c2c(c1)oc(=O)c1c3cc(O)c(O)cc3oc21</smiles>

(a)<smiles>CCC(CCC(C)C1CCC2C3CC=C4CC(O)CCC4(C)C3CCC12C)C(C)C</smiles>

(b)<smiles>CCC(/C=C\C(C)C1CCC2C3CC=C4CC(O)CCC4(C)C3CCC12C)C(C)C</smiles>

(c)

Figure 5: (a) Wedelolactone (b) $\beta$-sitosterol (c) Stigmasterol.

The enthalpy of adsorption $(\Delta H)$ was calculated

$$
\Delta H=E_{a}-R T,
$$

and the entropy of adsorption $(\Delta S)$ was calculated using

$$
\Delta G=\Delta H-T \Delta S .
$$

The calculated values of activation energy $\left(E_{a}\right)$, enthalpy of adsorption $(\Delta H)$, free energy of adsorption $(\Delta G)$, and entropy of adsorption $(\Delta S)$ are shown in Table 6.

The activation energy $E_{a}$ was found to be $31.38 \mathrm{KJ} \mathrm{mol}^{-1}$ for $(1 \mathrm{~N} \mathrm{HCl})$ and increased to $62.41 \mathrm{KJ} \mathrm{mol}^{-1}$ in the presence of the Adathoda vasica extract and $93.48 \mathrm{KJ} \mathrm{mol}^{-1}$ for Eclipta alba which shows that the adsorbed organic matter has provided a physical barrier to charge and mass transfer, leading to reduction in corrosion rate. The higher value of $E_{a}$ in the presence of the inhibitor compared to that in the absence of the inhibitor was attributed to physisorption [4]. For Centella asiatica, $E_{a}$ was found to be $31.33 \mathrm{KJ} \mathrm{mol}^{-1}$ and remained almost same as blank suggesting inhibition efficiency had not changed with temperature variation for Centella asiatica.

The values of $\Delta G_{\mathrm{ads}}$ around $-20 \mathrm{KJ} \mathrm{mol}^{-1}$ or lower are consistent with the electrostatic interaction between organic charged molecules, and the charged metal (physisorption) and those around $-40 \mathrm{KJ} \mathrm{mol}^{-1}$ or higher involved charge sharing or transfer from the organic molecules to the metal surface to form a coordinate type of bond (chemisorption) as discussed by Moretti et al. [38]. In this case, the negative sign of free energy of adsorption for the plant extracts indicates that the adsorption of the plant extracts on mild steel surface was a spontaneous process and the adsorption could be physisorption. Studies of El-Etre [3] and Li et al. [5] reported similar kind of results. The positive value of enthalpy of adsorption $(\Delta H)$ suggests that the reaction was endothermic and the adsorption of the inhibitor on the metal surface has taken place. Positive value of entropy of adsorption $(\Delta S)$ indicates that the reaction was spontaneous and feasible. Earlier work of Bhajiwala and Vashi [39] supports this. 


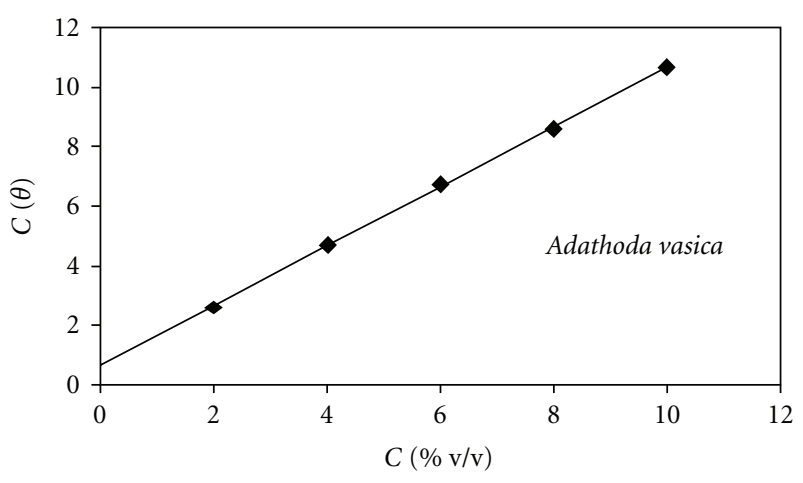

(a)

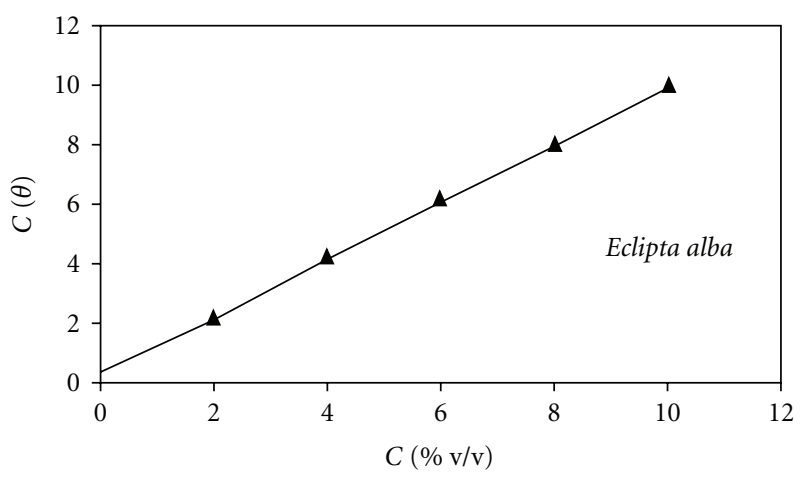

(b)

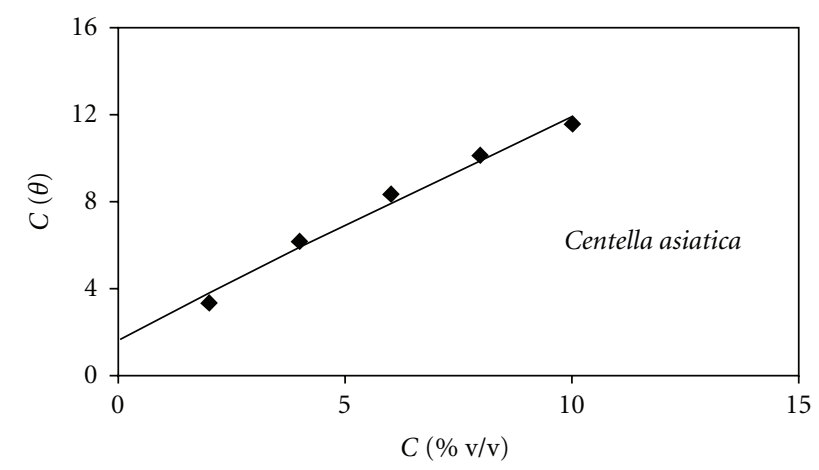

(c)

FIGURE 6: Langmuir adsorption isotherm plot for the adsorption of various concentrations of the plant extracts on the surface of mild steel in $1 \mathrm{~N} \mathrm{HCl}$ solution.

3.6. Surface Examination Studies. Surface examination of the mild steel specimens was made using JEOL—scanning electron microscope (SEM) with the magnification of 1000x. The mild steel specimens after immersion in $1 \mathrm{~N} \mathrm{HCl}$ solution for three hours at $30^{\circ} \mathrm{C}$ in the absence and presence of optimum concentration of the plant extracts were taken out, dried, and kept in a dessicator. The protective film formed on the surface of the mild steel was confirmed by SEM studies. The SEM images of mild steel immersed in $1 \mathrm{~N} \mathrm{HCl}$ in the absence and presence of the optimum concentration of the plant extracts are shown in Figures 7, 8, 9, and 10. From the SEM images, it was found that more grains were found in SEM image of mild steel immersed in $1 \mathrm{~N} \mathrm{HCl}$ solution in the absence of the inhibitor, whereas no grains were found in the SEM image of mild steel immersed in $1 \mathrm{~N} \mathrm{HCl}$ solution in the presence of the plant extracts, which shows the presence of a protective film over the surface of the mild steel in the presence of the inhibitors and the protective film is uniform in the order Eclipta alba $>$ Adathoda vasica $>$ Centella asiatica. The SEM morphology of the adsorbed protective film on the mild steel surface has confirmed the high performance of inhibitive effect of the plant extracts.

3.7. Hydrogen Permeation Studies. When metals are in contact with acids, atomic hydrogen is produced. Before they combine to produce hydrogen molecules, a fraction may diffuse into the metal. Inside the metal, the hydrogen atoms may combine to form molecular hydrogen. Thus,

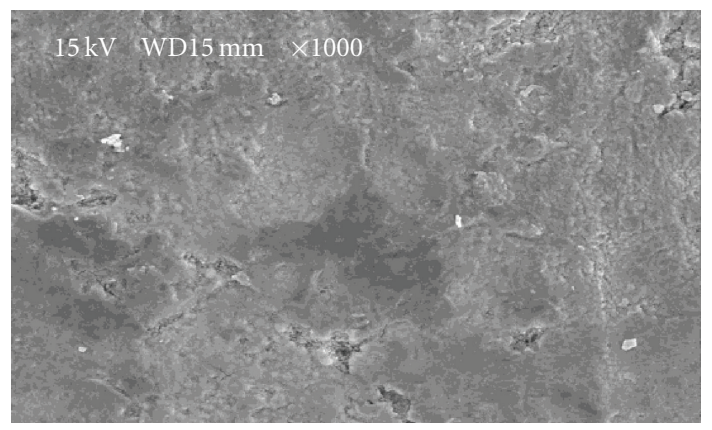

FIgure 7: SEM photograph of mild steel immersed in $1 \mathrm{~N} \mathrm{HCl}$ solution (blank).

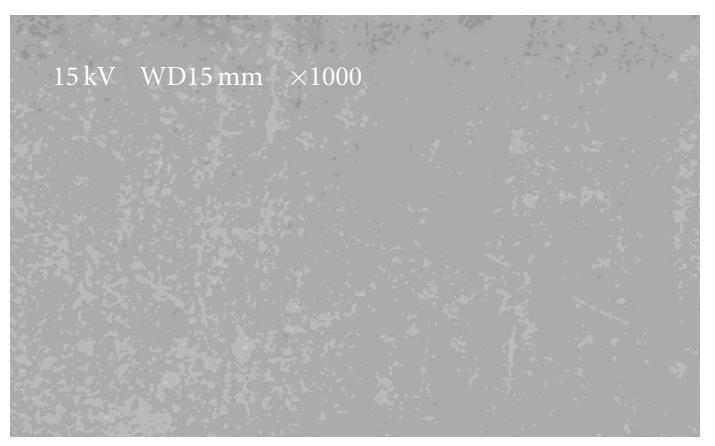

FIGURE 8: SEM photograph of mild steel immersed in $1 \mathrm{~N} \mathrm{HCl}$ solution containing an optimum conc. ( $8 \% \mathrm{v} / \mathrm{v})$ of Eclipta alba. 
TABLE 6: Calculated values of activation energy $\left(E_{a}\right)$, enthalpy of adsorption $(\Delta H)$, free energy of adsorption $(-\Delta G)$, and entropy of adsorption $(\Delta S)$ in the absence and presence of the optimum concentration of the plant extracts.

\begin{tabular}{|c|c|c|c|c|c|}
\hline System & Temp $(T)$ in $\mathrm{K}$ & $E_{a}\left(\mathrm{KJ} \mathrm{mol}^{-1}\right)$ & $\Delta H\left(\mathrm{KJ} \mathrm{mol}^{-1}\right)$ & $\Delta G\left(\mathrm{KJ} \mathrm{mol}^{-1}\right)$ & $\Delta S\left(\mathrm{KJ} \mathrm{mol}^{-1}\right)$ \\
\hline \multirow{6}{*}{ Blank } & 303 & \multirow{6}{*}{31.38} & 28.86 & & \\
\hline & 313 & & 28.78 & & \\
\hline & 323 & & 28.69 & & \\
\hline & 333 & & 28.61 & & \\
\hline & 343 & & 28.53 & & \\
\hline & 353 & & 28.45 & & \\
\hline \multirow{6}{*}{ Adathoda vasica $6 \% \mathrm{v} / \mathrm{v}$} & 303 & \multirow{6}{*}{62.41} & 59.89 & -17.18 & 0.2544 \\
\hline & 313 & & 59.81 & -17.27 & 0.2463 \\
\hline & 323 & & 59.72 & -16.71 & 0.2367 \\
\hline & 333 & & 59.64 & -16.42 & 0.2284 \\
\hline & 343 & & 59.56 & -15.26 & 0.2181 \\
\hline & 353 & & 59.48 & -14.82 & 0.2105 \\
\hline \multirow{6}{*}{ Eclipta alba $8 \% \mathrm{v} / \mathrm{v}$} & 303 & \multirow{6}{*}{93.48} & 90.96 & -18.78 & 0.3622 \\
\hline & 313 & & 90.88 & -16.31 & 0.3425 \\
\hline & 323 & & 90.79 & -15.04 & 0.3277 \\
\hline & 333 & & 90.71 & -14.02 & 0.3145 \\
\hline & 343 & & 90.63 & -13.22 & 0.3028 \\
\hline & 353 & & 90.55 & -11.29 & 0.2885 \\
\hline \multirow{6}{*}{ Centella asiatica $10 \% \mathrm{v} / \mathrm{v}$} & 303 & \multirow{6}{*}{31.33} & 28.81 & -8.75 & 0.1240 \\
\hline & 313 & & 28.73 & -9.04 & 0.1207 \\
\hline & 323 & & 28.64 & -9.28 & 0.1174 \\
\hline & 333 & & 28.56 & -9.68 & 0.1148 \\
\hline & 343 & & 28.48 & -9.88 & 0.1118 \\
\hline & 353 & & 28.40 & -10.19 & 0.1093 \\
\hline
\end{tabular}

TABLE 7: Values of hydrogen permeation current for the corrosion of mild steel in $1 \mathrm{~N} \mathrm{HCl}$ alone and in the presence of inhibitors.

\begin{tabular}{lccc}
\hline Inhibitor & Conc. of the extract $(\%$ in v/v) & Permeation current $(\mu \mathrm{A})$ & Reduction in permeation current $(\%)$ \\
\hline Blank & - & 23.0 & - \\
Adathoda vasica & 6.0 & 3.1 & 86.52 \\
Eclipta alba & 8.0 & 2.2 & 90.43 \\
Centella asiatica & 10.0 & 19.4 & 15.65 \\
\hline
\end{tabular}

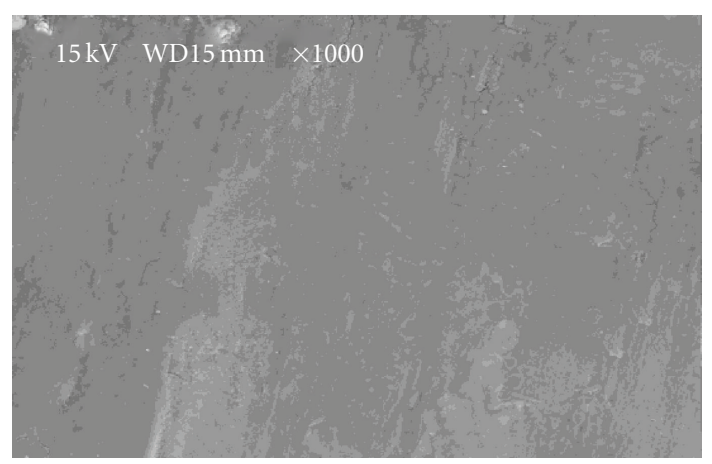

FIGURE 9: SEM photograph of mild steel immersed in $1 \mathrm{~N} \mathrm{HCl}$ solution containing an optimum conc. $(6 \% \mathrm{v} / \mathrm{v})$ of Adathoda vasica.

a very high internal pressure is built up. This leads to heavy damage of the metal. This is known as "hydrogen embrittlement". This phenomenon of hydrogen entry into

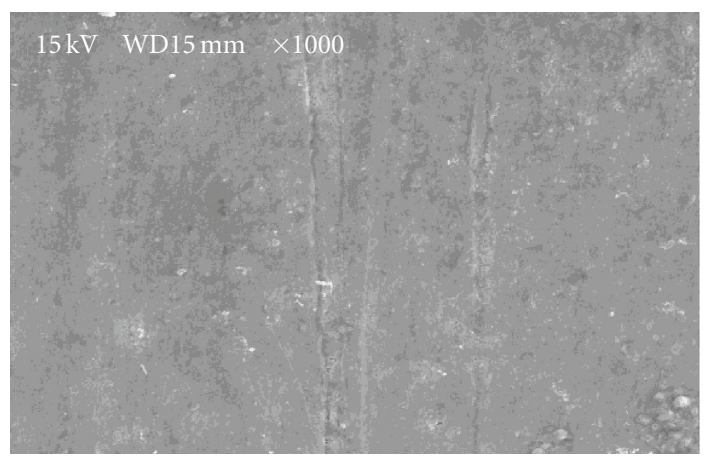

FIGURE 10: SEM photograph of mild steel immersed in $1 \mathrm{~N} \mathrm{HCl}$ solution containing an optimum conc. $(10 \% \mathrm{v} / \mathrm{v})$ of Centella asiatica.

the metals can occur in industrial processes like pickling, plating, phosphating, and so forth. An inhibitor can be considered as completely effective only if it simultaneously 
inhibits metal dissolution and hydrogen penetration into the metal [40]. Hydrogen permeation study has been taken up with an idea of screening the inhibitors with regard to their effectiveness on the reduction of hydrogen uptake. The behaviour of the inhibitors with regard to hydrogen permeation can be understood by measuring the permeation current with and without inhibitors [30].

There are basically two reaction schemes. Common to both schemes, the first step is the diffusion of few hydrogen atoms that get onto the electrode surface. Hydrated protons are reduced to form neutral hydrogen atoms upon those areas of the surface, which are unoccupied. One can say protons are discharged on to free sites on the electrode to form adsorbed hydrogen atoms

$$
\mathrm{M}(\mathrm{e})+\mathrm{H}_{3} \mathrm{O}^{+} \longrightarrow \mathrm{MH}_{\mathrm{ads}}+\mathrm{H}_{2} \mathrm{O}
$$

where $\mathrm{M}$ is the cathodic metal surface. The second step is the desorption step. The two basic reaction paths are

(i) discharge $\mathrm{D}$, followed by chemical desorption, CD,

$$
\mathrm{MH}_{\mathrm{ads}}+\mathrm{MH}_{\mathrm{ads}} \longrightarrow 2 \mathrm{M}+\mathrm{H}_{2} \uparrow
$$

(ii) discharge D, followed by electrolytic desorption, ED,

$$
\mathrm{MH}_{\mathrm{ads}}+\mathrm{H}_{3} \mathrm{O}^{+}+\mathrm{M}(\mathrm{e}) \longrightarrow 2 \mathrm{M}+\mathrm{H}_{2} \mathrm{O}+\mathrm{H}_{2} \uparrow .
$$

For transition metals, it has been reported that the electrolytic desorption is the rate determining step. A part of the atomic hydrogen liberated during these processes enters the metal, when the remainder is evolved as hydrogen gas [40]. From the hydrogen permeation studies on mild steel in $1 \mathrm{~N} \mathrm{HCl}$ in the absence and presence of inhibitors, it was observed that all the prepared extracts were able to reduce the permeation current compared to the control. The decrease in the permeation current follows the order Eclipta alba $>$ Adathoda vasica > Centella asiatica. Permeation current versus time curves for mild steel in $1 \mathrm{~N} \mathrm{HCl}$ in the absence and presence of inhibitors are shown in Figure 11, and their corresponding permeation are given in Table 7 .

The reason for the reduced permeation currents in presence of the inhibitors can be attributed to the slow discharge step followed by fast electrolytic desorption step

$$
\begin{gathered}
\mathrm{M}(\mathrm{e})+\mathrm{H}_{3} \mathrm{O}^{+} \stackrel{\text { slow }}{\longrightarrow} \mathrm{MH}_{\text {ads }}+\mathrm{H}_{2} \mathrm{O}, \\
\mathrm{MH}+\mathrm{H}_{3} \mathrm{O}^{+}+\mathrm{M}(\mathrm{e}) \stackrel{\text { fast }}{\longrightarrow} 2 \mathrm{M}+\mathrm{H}_{2} \mathrm{O}+\mathrm{H}_{2} .
\end{gathered}
$$

The reduction of hydrogen uptake could be attributed to adsorption of the phytochemical constituents present in the plant extracts on the mild steel surface, which prevented permeation of hydrogen into metal.

\section{Conclusion}

(1) The leaf extracts of Adathoda vasica, Eclipta alba, and Centella asiatica act as good and efficient inhibitors for corrosion of mild steel in $1 \mathrm{~N}$ Hydrochloric acid.

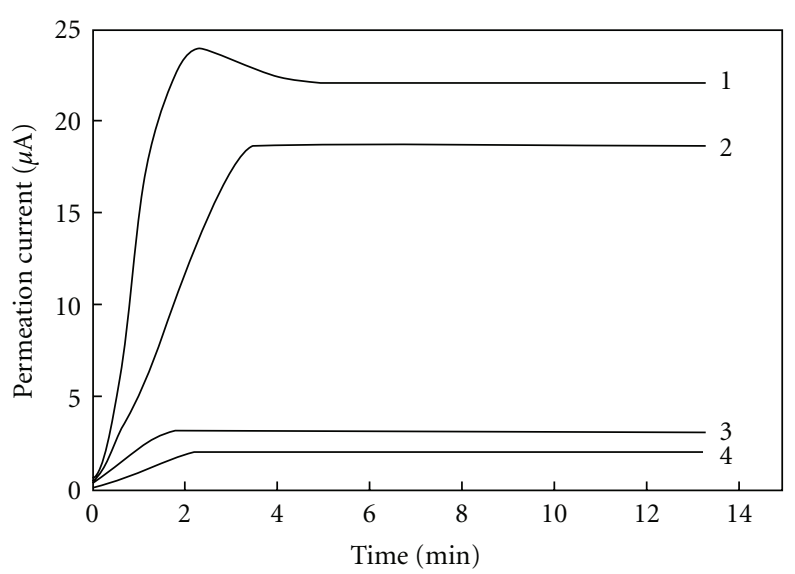

Figure 11: (1) Blank (2) Centella asiatica (10\%v/v) (3) Eclipta alba $(8 \% \mathrm{v} / \mathrm{v})(4)$ Adathoda vasica $(6 \% \mathrm{v} / \mathrm{v})$ Hydrogen permeation current versus time plots for mild steel in $1 \mathrm{~N} \mathrm{HCl}$ solution in the absence and presence of an optimum concentration of the plant extracts.

(2) The maximum inhibition efficiency for Eclipta alba extract was found to be $99.6 \%$ in the optimum concentration $8 \%$ in $\mathrm{v} / \mathrm{v}$, for Adathoda vasica extract, $99.0 \%$ in the optimum concentration $6 \%$ in $\mathrm{v} / \mathrm{v}$, and for Centella Asiatica extract, $85.3 \%$ in the optimum concentration $10 \%$ in $\mathrm{v} / \mathrm{v}$.

(3) The effect of immersion time of all the plant extracts at the optimum concentration showed maximum efficiency in $3 \mathrm{~h}$ immersion time at $30^{\circ} \mathrm{C}$ and found sufficient for pickling process.

(4) Potentiodynamic polarization studies revealed that the extracts act through mixed mode of inhibition.

(5) The impedance method revealed that charge-transfer process mainly controls the corrosion of mild steel.

(6) The adsorption of different concentrations of the plant extracts on the surface of mild steel in $1 \mathrm{~N}$ hydrochloric acid followed Langmuir adsorption isotherm.

(7) The effect of temperature revealed physical adsorption for the inhibition action of these plant extracts.

(8) The value of activation energy $E_{a}$ revealed that the adsorbed organic matter provided a physical barrier to charge and mass transfer, leading to reduction in corrosion rate.

(9) The negative sign of free energy of adsorption indicates that the adsorption of the inhibitor on mild steel surface was a spontaneous process and the adsorption was found to be physisorption.

(10) The positive value of enthalpy of adsorption $(\Delta H)$ suggests that the reaction was endothermic and the adsorption of the inhibitors on the metal surface takes place.

(11) A positive value of entropy of adsorption $(\Delta S)$ indicates that the reaction was spontaneous and feasible. 
(12) The SEM morphology of the adsorbed protective film on the mild steel surface has confirmed the high performance of inhibitive effect of the plant extracts.

(13) From hydrogen permeation method, it was observed that all the plant extracts were able to reduce the permeation current compared to the control.

(14) Results obtained in weight loss method were very much in good agreement with the electrochemical methods and Hydrogen permeation method in the order Eclipta alba > Adathoda vasica > Centella asiatica, and among the three plant extracts studied, the maximum inhibition efficiency was found in Eclipta alba which showed $99.6 \%$ inhibition efficiency at $8.0 \% \mathrm{v} / \mathrm{v}$ concentration of the extract.

\section{References}

[1] M.A. Quraishi and D. K. Yadav, "Corrosion and its control' by some green Inhibitors," in Proceedings of the 14th National Congress on Corrosion Control, 2008.

[2] A. Bouyanzer, B. Hammouti, and L. Majidi, "Pennyroyal oil from Mentha pulegium as corrosion inhibitor for steel in $1 \mathrm{M}$ HCl," Materials Letters, vol. 60, no. 23, pp. 2840-2843, 2006.

[3] A. Y. El-Etre, "Inhibition of aluminum corrosion using Opuntia extract," Corrosion Science, vol. 45, no. 11, pp. 24852495, 2003.

[4] K. O. Orubite and N. C. Oforka, "Inhibition of the corrosion of mild steel in hydrochloric acid solutions by the extracts of leaves of Nypa fruticans Wurmb," Materials Letters, vol. 58, no. 11, pp. 1768-1772, 2004.

[5] Y. Li, P. Zhao, Q. Liang, and B. Hou, "Berberine as a natural source inhibitor for mild steel in $1 \mathrm{M} \mathrm{H}_{2} \mathrm{SO}_{4}$," Applied Surface Science, vol. 252, no. 5, pp. 1245-1253, 2005.

[6] A. Y. El-Etre, M. Abdallah, and Z. E. El-Tantawy, "Corrosion inhibition of some metals using lawsonia extract," Corrosion Science, vol. 47, no. 2, pp. 385-395, 2005.

[7] E. Emeka and Oguzie, "Studies on the inhibitive effect of Occimum viridis extract on the acid corrosion of mild steel," Materials Chemistry and Physics, vol. 99, no. 2-3, pp. 441-446, 2005.

[8] G. Gunasekaran and L. R. Chauhan, "Eco friendly inhibitor for corrosion inhibition of mild steel in phosphoric acid medium," Electrochimica Acta, vol. 49, no. 25, pp. 4387-4395, 2004.

[9] I. B. Obot, S. A. Umoren, and N. O. Obi-Egbedi, "Corrosion inhibition and adsorption behaviour for aluminuim by extract of Aningeria robusta in $\mathrm{HCl}$ solution: synergistic effect of iodide ions," Journal of Materials and Environmental Science, vol. 2, no. 1, pp. 60-71, 2011.

[10] H. Al-Sehaibani, "Evaluation of Henna leaves as environmentally friendly corrosion inhibitors for metals," Materialwissenschaft andWerkstofftechnik, vol. 31, no. 2, pp. 1060-1063, 2000.

[11] M. Lebrini, F. Robert, and C. Roos, "Inhibition effect of alkaloids extract from Annona squamosa plant on the corrosion of C38 steel in normal hydrochloric acid medium," International Journal of Electrochemical Science, vol. 5, no. 11, pp. 1698$1712,2010$.

[12] C. A. Loto and A. I. Mohammed, "The effect of Anacardium Occidentale (cashew) juice extract on the corrosion of mild steel in hydrochloric acid," Corrosion Prevention and Control
Journal, vol. 47, no. 2, pp. 5056-5063, 2000.

[13] G. D. Davis, The Use of Extracts of Tobacco Plants as Corrosion Inhibitors, DACCO SCI, INC, Columbia, Md, USA, 2000.

[14] O. K. Abiola, "The inhibition of mild steel corrosion in an acidic medium by fruit juice of citrus paradisi," Journal of Corrosion Science and Engineering, vol. 5, no. 10, 2006.

[15] A. O. James and E. O. Ekpe, "Inhibition of corrosion of mild steel in $2 \mathrm{M}$ hydrochloric acid by Aloe Vera," International Journal of Pure and Applied Chemistry, vol. 35, no. 10, 2002.

[16] M. Lebrini, F. Robert, and C. Roos, "Alkaloids extract from Palicourea guianensis plant as corrosion inhibitor for C38 steel in $1 \mathrm{M}$ hydrochloric acid medium," International Journal of Electrochemical Science, vol. 6, no. 3, pp. 847-859, 2011.

[17] J. Bruneton, Pharmacognosie-Phytochimie, Plantes Médicinales, Médicinales Internationales, Tec\&Doc, Paris, France, 4ème edition, 2009.

[18] E. E. Ebenso, N. O. Eddy, and A. O. Odiongenyi, "Corrosion inhibitive properties and adsorption behaviour of ethanol extract of Piper guinensis as a green corrosion inhibitor for mild steel in $\mathrm{H}_{2} \mathrm{SO}_{4}$," African Journal of Pure and Applied Chemistry, vol. 2, no. 11, pp. 107-115, 2008.

[19] I. M. Mejeha, A. A. Uroh, K. B. Okeoma, and G. A. Alozie, "The inhibitive effect of Solanum melongena L. leaf extract on the corrosion of aluminium in tetraoxosulphate (VI) acid," African Journal of Pure and Applied Chemistry, vol. 4, no. 8, pp. 158-165, 2010.

[20] A. Y. El-Etre, "Inhibition of acid corrosion of carbon steel using aqueous extract of olive leaves," Journal of Colloid and Interface Science, vol. 314, no. 2, pp. 578-583, 2007.

[21] A. M. Abdel-Gaber, B. A. Abd-El-Nabey, I. M. Sidahmed, A. M. El-Zayady, and M. Saadawy, "Inhibitive action of some plant extracts on the corrosion of steel in acidic media," Corrosion Science, vol. 48, no. 9, pp. 2765-2779, 2006.

[22] A. M. Abdel-Gaber, B. A. Abd-El-Nabey, and M. Saadawy, "The role of acid anion on the inhibition of the acidic corrosion of steel by lupine extract," Corrosion Science, vol. 51, no. 5, pp. 1038-1042, 2009.

[23] B. Anand and V. Balasubramanian, "Corrosion behaviour of mild steel in acidic medium in presence of aqueous extract of Allamanda blanchetii," E-Journal of Chemistry, vol. 8, no. 1, pp. 226-230, 2011.

[24] M. H. Hussin and M. J. Kassim, "Electrochemical studies of mild steel corrosion inhibition in aqueous solution by Uncaria gambir extract," Journal of Physical Sciences, vol. 21, pp. 1-13, 2010.

[25] A. M. Al-Turkustani, "Aloe plant extract as environmentally friendly inhibitor on the corrosion of aluminum in hydrochloric acid in absence and presence of iodide ions," Modern Applied Science, vol. 4, pp. 105-124, 2010.

[26] S. Rajendran, M. Agasta, R. B. Devi, B. S. Devi, K. Rajam, and J. Jeyasundari, "Corrosion inhibition by an aqueous extract of Henna leaves (Lawsonia Inermis L)," Zaštita Materijala, vol. 50, pp. 77-84, 2009.

[27] J. A. Selvi, S. Rajendran, V. G. Sri, A. J. Amalraj, and B. Narayanasamy, "Corrosion inhibition by beet root extract," Portugaliae Electrochimica Acta, vol. 27, pp. 1-11, 2009.

[28] G. Ilayaraja, A. R. Sasieekhumar, and P. Dhanakodi, "Inhibition of mild steel corrosion in acidic medium by aqueous extract of Tridax procumbens L.," E-Journal of Chemistry, vol. 8, no. 2, pp. 685-688, 2011.

[29] M.A.V. Devanathan and Z. Stachurski, "The Adsorption and diffusion of electrolytic hydrogen in palladium," Proceedings of Royal Society, vol. 70, p. 10, 1962.

[30] J. O. M. Bockris, J. McBreen, and L. Nanis, "The hydrogen 
evolution kinetics and hydrogen entry into a-iron," Journal of The Electrochemical Society, vol. 112, no. 10, pp. 1025-1031, 1965.

[31] M. J. Danielson, "Use of the Devanathan-Stachurski cell to measure hydrogen permeation in aluminum alloys," Corrosion Science, vol. 44, no. 4, pp. 829-840, 2002.

[32] M. A. Quraishi and J. Rawat, "Influence of iodide ions on inhibitive performance of tetraphenyl-dithia-octaazacyclotetradeca-hexaene (PTAT) during pickling of mild steel in hot sulfuric acid," Materials Chemistry and Physics, vol. 70, no. 1, pp. 95-99, 2001.

[33] http://www.himalayahealthcare.com/herbfinder/english.htm.

[34] K. K. Bhargava, "Himalaya herbal monograph," Indian Journal of Chemistry, vol. 8, p. 664, 1970.

[35] M. J. Sanghvi, S. K. Shukla, A. N. Misra, M. R. Padh, and G. N. Mehta, "Inhibition of hydrochloric acid corrosion of mild steel by aid extracts of Embilica officianalis, Terminalia bellirica and Terminalia chebula," Bulletin of Electrochemistry, vol. 13, no. 8-9, pp. 358-361, 1997.

[36] A. A. El Hosary, R. M. Saleh, and A. M. Shams-Eldin, "Corrosion inhibition by naturally occurring substances-1. The effect of hibiscus subdariffa (Karkade) extract on the dissolution of $\mathrm{Al}$ and Zn," Corrosion Science, vol. 12, pp. 897904, 1972.

[37] M. Ajmal, A. S. Mideen, and M. A. Quraishi, "2-hydrazino6-methyl-benzothiazole as an effective inhibitor for the corrosion of mild steel in acidic solutions," Corrosion Science, vol. 36, no. 1, pp. 79-84, 1994.

[38] G. Moretti, F. Guidi, and G. Grion, "Tryptamine as a green iron corrosion inhibitor in $0.5 \mathrm{M}$ deaerated sulphuric acid," Corrosion Science, vol. 46, no. 2, pp. 387-403, 2004.

[39] H. M. Bhajiwala and R. T. Vashi, "Ethylamines as corrosion inhibitors for zinc in $\mathrm{HNO} 3$ / $\mathrm{HCl}$ binary mixture," Bulletin of Electrochemistry, vol. 18, no. 6, pp. 261-266, 2002.

[40] K. N. Srinivasan, M. Selvam, and S. Venkata Krishna Iyer, "Hydrogen permeation during zinc-manganese alloy plating," Journal of Applied Electrochemistry, vol. 23, no. 4, pp. 358-363, 1993. 

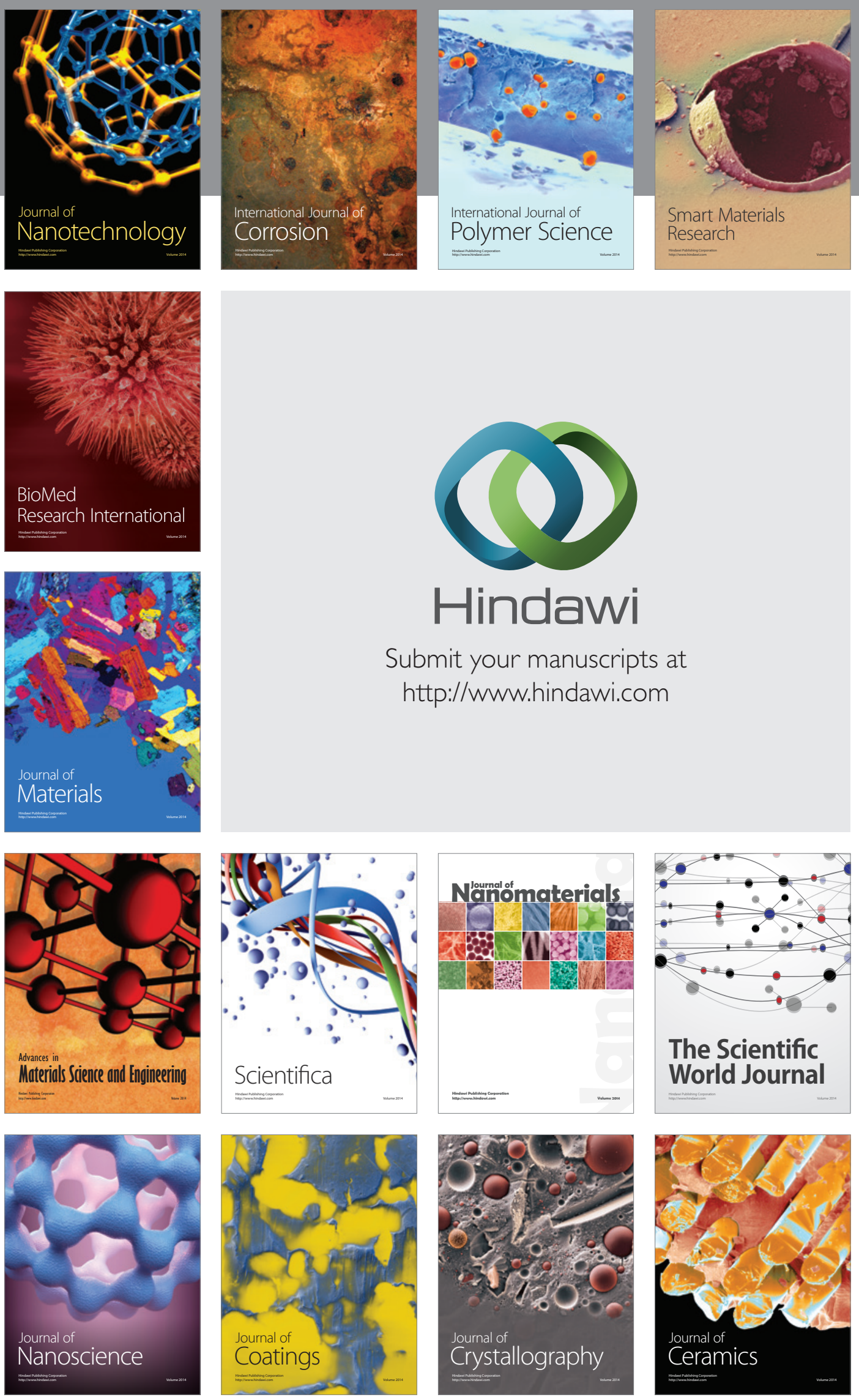

The Scientific World Journal

Submit your manuscripts at

http://www.hindawi.com

\section{World Journal}

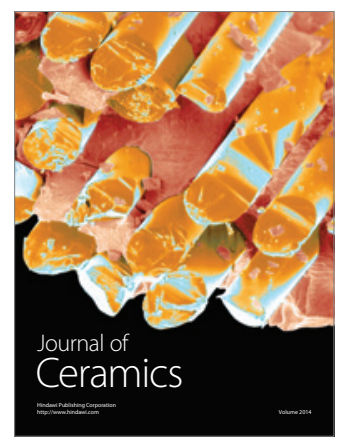

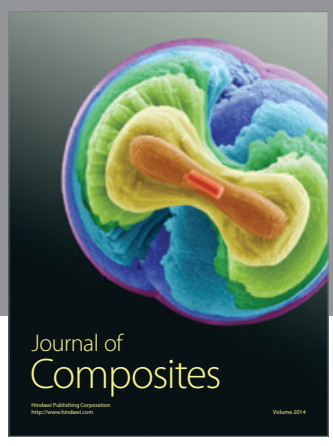
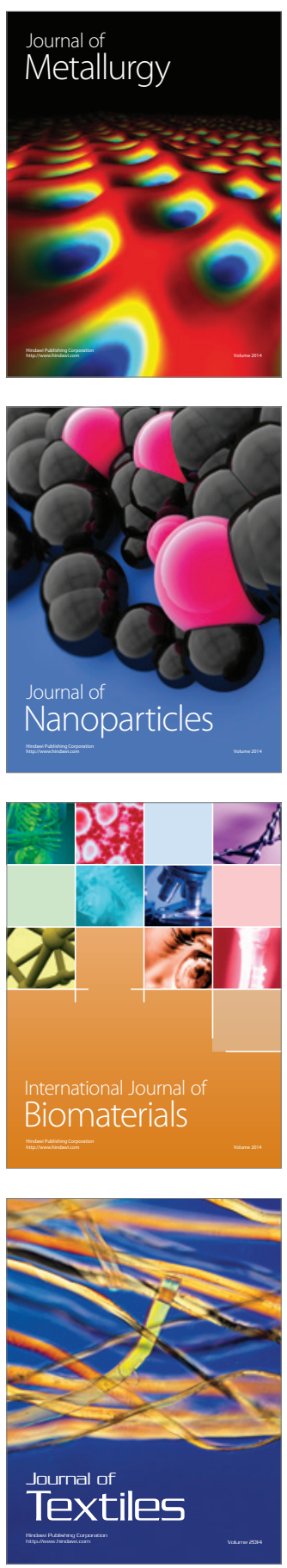